\title{
Elucidating a Particulate Matter Deposition Episode by Combining Scanning Electron Microscopy and X-Ray Fluorescence Spectrometry
}

\author{
Cristina Vázquez, Graciela Custo, Laura Dawidowski, Darío Gómez, Marina ViLlegas, \\ Martha ORTIZ, and Mayumi MiYAgusukU
}

Unidad de Actividad Química, Comisión Nacional de Energía Atómica, Av. Gral Paz 1499 (B1650KNA), San Martín, Buenos Aires, Argentina

\begin{abstract}
Multielemental composition and morphology of particulate matter samples were examined to detect the presence of two potential responsible pollutant emitters at four sites impacted during a pollution episode in the City of Campana, Argentina. Coke and smoke black are the main constituents associated to the industrial plants that were considered, $a$ priori, as responsible pollutant emitters. Wavelength dispersive X-ray fluorescence (WDXRF) was employed for the analysis of metals in samples coming from both, suspected sources and four sites. On the basis of multielemental composition profiles, a screening analysis was undertaken for exploring similarities among sources and sample sites adopting the average concentration profile of the crustal rock as soil surrogate. Particle morphology was studied by scanning electron microscopy (SEM) in source samples and in those environmental samples selected through the screening analysis. Two types of collected samples were analyzed: 1) those with composition profiles closer to the potential sources and 2) those closer to the cluster rock. This strategy was adequate to identify the responsible source of the contamination episode.
\end{abstract}

(Received January 7, 2005; Accepted March 17, 2005)

\section{Introduction}

Campana is an industrial city located at about $100 \mathrm{~km} \mathrm{NW}$ of Buenos Aires, the capital of Argentina, and holds a considerable activity that includes two oil refineries, a steelwork and several industrial facilities that are distributed as a pair of pincers embracing the urban area (Fig. 1). During three days period an unusual episode of contamination occur in the city: people perceived the deposition of dark airborne particles with a tendency to adhere to exposed surfaces. On the basis of the color and adherence of the deposited particles, the Environmental Protection Department (EPD) of the city, selected two industrial sources-one of the refineries and a smoke black manufacturing plant-to explore their responsibility in the pollution episode. Soot was discarded by the EPD as an alternate source after checking that the natural gas was the fuel burned by the industrial and residential sectors during the episode. Although some efforts have been already undertaken to characterize the air quality in the City of Campana,${ }^{1}$ no information is thus far available on chemical composition or morphology of suspended particulate matter sources.

One of the major tasks regarding environmental particles is to make a source assignment of the collected aerosol and to evaluate the contribution to pollution from local or distant sources. In this sense, this paper aims to relate the composition

$\dagger$ To whom correspondence should be addressed.

E-mail: Cristina.Vazquez@cnea.gov.ar of the particulate matter sampled at four collected sites to that of particles sampled at the two suspected responsible sources. Taking into account the unrepeatable of the pollution episode, conservation of collected samples was mandatory to be facing further investigations. In this sense, X-ray techniques are the better candidates providing multielemental information for a single measurement in a reasonable period of time, using small amount of sample and the most important features for this episode is the non-destructive characteristic of the analysis. ${ }^{2-6}$

In this paper, a combined WDXRF and SEM approach has been applied to clarify the pollution episode. The characterization of both sources done in this work may be used

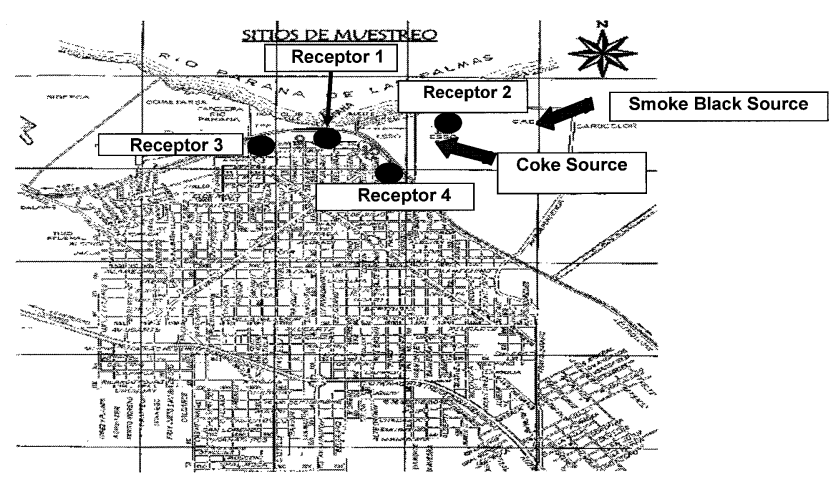

Fig. 1 Map of Campana City showing the localization of two suspected sources and the four receptor places. 
Table 1 Composition profiles of receptors, sources samples and crustal rock

\begin{tabular}{|c|c|c|c|c|c|c|c|c|}
\hline \multirow{2}{*}{ Sample } & \multicolumn{8}{|c|}{ Concentration $/ \mu \mathrm{g} \mathrm{g}^{-1}$} \\
\hline & $\mathrm{Ca}$ & $\mathrm{Ti}$ & $\mathrm{Mn}$ & $\mathrm{Fe}$ & $\mathrm{Ni}$ & $\mathrm{Cu}$ & $\mathrm{Zn}$ & $\mathrm{Se}$ \\
\hline Receptor 1 & 51000 & 2100 & 275 & 30000 & 34 & 199 & 88 & 8 \\
\hline Receptor $2 \mathrm{a}$ & 25000 & 1800 & 1120 & 50800 & 40 & 59 & 381 & 2 \\
\hline Receptor $2 b$ & 13500 & 1100 & 600 & 32000 & 23 & 45 & 1052 & 10 \\
\hline Receptor 3a & 49000 & 5000 & 584 & 53000 & 11 & 41 & 255 & 25 \\
\hline Receptor $3 b$ & 33000 & 2600 & 451 & 24000 & 4 & 39 & 95 & 2 \\
\hline Receptor 4 & 6100 & 200 & 136 & 4000 & 9 & 80 & 170 & 2 \\
\hline Coke dust & 6200 & 700 & 120 & 9900 & 147 & 20 & 77 & 2 \\
\hline Smoke black-fluffy & 4000 & 1100 & ND & 600 & 26 & 20 & 34 & 2 \\
\hline Smoke black-pelletized & 4300 & 400 & ND & 700 & 44 & 20 & 48 & 2 \\
\hline Crustal rock & 36300 & 4400 & 950 & 50000 & 75 & 55 & 70 & 0.05 \\
\hline
\end{tabular}

ND: Below limit of detection.

not only for the objectives of the study but also for contributing to a database that will be needed for a future assessment on the provenance of the airbone particulate matter of the zone.

\section{Experimental}

Samples

The unexpected nature of the episode made that any predetermined sample collection were possible. Samples coming from the contaminated sites were collected as careful as possible out of the surfaces where they had deposited. Most collected samples contained other types of particles that are not necessarily related to the potential sources responsible for the event. Particularly, they contained soil dust since the episode occurred during a dry season (rainfall at the episode time was at the minimum historical levels of the place and no rain occurred during the eight days before the episode). The staff of the EPD collected the deposited samples as well as source samples. Samples coming from the refinery were taken from coke stockpiles while two kinds of smoke black samples were taken at the industrial facility: fluffy and pelletized. Particularly attention was made with samples coming from sites 2 and 3 do to the visible inhomogeneity, showing large black particles clearly differentiated of grizzled particles with smaller size. Consequently, originally colleted particles from sites 2 and 3 were manually separated in two parts apiece: parts $2 \mathrm{a}$ and $3 \mathrm{a}$ contained the grayish portion while $2 b$ and $3 b$ contained the darker portion.

Taking into account the low mass collected (approximately $200 \mathrm{mg}$ ), a compacting procedure over $500 \mathrm{mg}$ of cellulose backing was selected as sample preparation for WDXRF analysis. Pressed pellets were made in a stainless-steel small matrix (diameter $1.5 \mathrm{~cm}$ ) at 10 tons during $60 \mathrm{~s}$. Because of the different size among the sampler holder $(4 \mathrm{~cm})$ and pressed discs, a special sample support was developed. The supports were made in acrylic at the laboratory according to the following procedure. A cellulose pellet, made in the same way as the sample described above, was placed in the center to cover of the pellet. After finishing the polymerization process, the cellulose pellet was pulled off, and a hole was left. The compacted sample was placed into this cavity for further irradiation in the spectrometer. The reference materials from NIST (Standard Reference Material SRM 1633a and SRM 1633b) coal fly ash was selected for calibrating the spectrometer.

For SEM analyis, particles were transferred to SEM specimen stubs, which were previously mounted with a double-stick adhesive tape, in several ways trying to minimize interference with the state that they were originally sampled. ${ }^{7}$ Specimens were coated with gold by direct current sputtering for SEM observations.

\section{Instrumental conditions}

A Philips PW 1410 wavelength dispersive X-ray fluorescence spectrometer equipped with a $\mathrm{W}$ anticathode X-ray tube was used. The tube was operated at $50 \mathrm{kV}$ and $25 \mathrm{~mA}$ using a scintillation counter for detection. $\mathrm{LiF}(200)$ crystal was employed as crystal diffraction for all elements except for $\mathrm{Cu}$ for where $\mathrm{LiF}(220)$ was used. $K_{\alpha}$ analytical lines and background intensities were measured for $120 \mathrm{~s}$ each in vacuum. The concentrations in the samples were determined using the ratio:

$$
C_{\text {is }}=I_{\text {st }} \times C_{\text {ist }} \times\left(I_{\text {ist }}\right)^{-1},
$$

where $C_{\text {is }}$ is the concentration of the $i$-th element in the sample, $I_{\mathrm{st}}$ the concentration of the $i$-th element in the reference standard, $C_{\text {ist }}$ the intensity of the X-ray line of the $i$-th element in the sample, and $I_{\text {ist }}$ the intensity of the X-ray line of the $i$-th element in the reference standard.

A Philips 515 was used for SEM observations. 10000× magnification was found to be the most adequate to detect similarities among sources and deposited samples.

\section{Results and Discussion}

\section{Screening analysis}

WDRXF analysis of $\mathrm{Ca}, \mathrm{Ti}, \mathrm{Mn}, \mathrm{Fe}, \mathrm{Ni}, \mathrm{Cu}, \mathrm{Zn}$ and $\mathrm{Se}$ in all samples were used to discriminated soil enriched collected samples from those with a lesser presence. These composition profiles served as a basis to classify all samples according to their similarity. In the absence of information on the chemical composition of soil dust, the crustal rock profile constitutes a good substitute for screening purposes. Table 1 shows the composition profiles measured and the average crustal rock composition used as surrogate for soil dust. ${ }^{8}$

Particles from both types of sources constitute carbon rich matrices with low levels of the elements measured compared with those of the samples. From the WDXRF results, $\mathrm{Ca}, \mathrm{Fe}$, $\mathrm{Mn}$ and Ti were selected as markers for crustal material for this particular set of samples. Both smoke black samples exhibit relatively low levels for the elements analyzed as compared to 


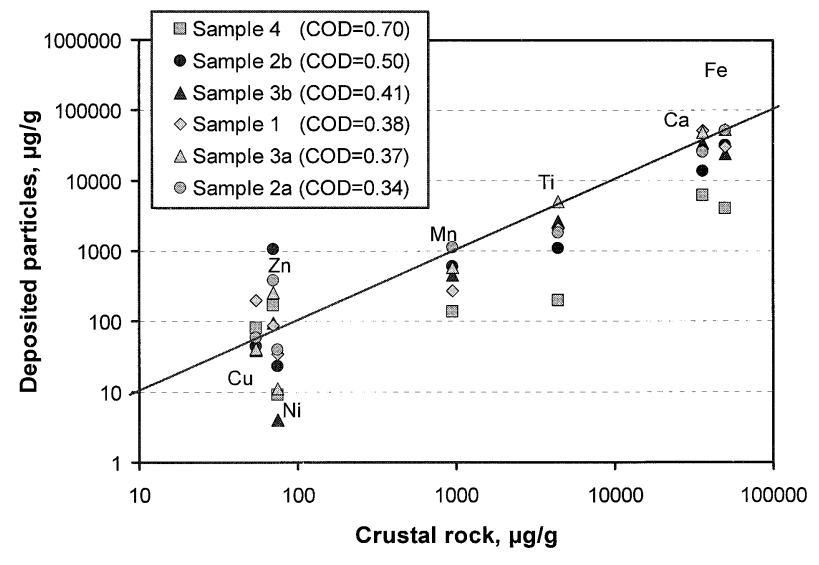

Fig. 2 Concentration diagram of receptor samples referred to the average crustal rock profile.

the other samples. This characteristic played a relevant role in the statistical treatment of the composition profiles. The levels of $\mathrm{Ni}, \mathrm{Fe}, \mathrm{Ca}, \mathrm{Cu}$ and $\mathrm{Zn}$ in the coke sample are comparable with literature values. ${ }^{9}$

Dissimilarity of chemical composition at different sample sites with respect to the crustal rock profile was studied through $\log$-log plots of concentrations. ${ }^{10}$ This type of concentration diagrams constitutes a useful representation that facilitates the comparison of samples with large concentration ranges for various components. Figure 2 shows the concentration profiles of all samples versus the average crustal rock profile. A sample is impoverished with respect to the crustal rock in those elements that lie below the diagonal or enriched for the elements above the line. Accompanying coefficients of divergence (COD), defined in Eq. (2), are also specified in the figure:

$$
\operatorname{COD}_{\mathrm{jk}}=\frac{1}{p} \sqrt{\sum_{i=1}^{p}\left(\frac{x_{\mathrm{ij}}-x_{\mathrm{ik}}}{x_{\mathrm{ij}}+x_{\mathrm{ik}}}\right)^{2}}
$$

where $x_{\mathrm{ij}}$ is the concentration of chemical component $\mathrm{i}$ at sample $\mathrm{j}, x_{\mathrm{ik}}$ the concentration of chemical component $\mathrm{i}$ in the crustal rock, and $p=8$ is the number of chemical components analyzed.

As the composition of a sample is similar to the crustal rock, COD approaches zero, as their composition diverges, COD approaches one. Under these considerations, sample 4 is noticeably distinct from the crustal rock and is therefore expected to contain the lesser amount of soil dust while sample $2 \mathrm{~b}$, which is somehow halfway between being enriched and impoverished of soil dust, is also a good candidate for further analysis.

Cluster analysis was used with the aim of grouping and classifying the set of all multielemental profiles-samples, sources, and crustal rock-on the basis of the relative presence of the measured elements. ${ }^{11-13}$ This classification is based on the similarity of the samples expressed according to a coefficient of dissimilarity. In this study, the coefficient chosen was the Euclidean distance.

Figure 3 shows the dendrogram obtained using Euclidean distances and a complete linkage, the representation on the basis of measured concentrations allows appreciating the distances among all objects in the original units of measurement. It is clearly noted that only two distinct clusters, one associated to the potential sources under study and another linked to the

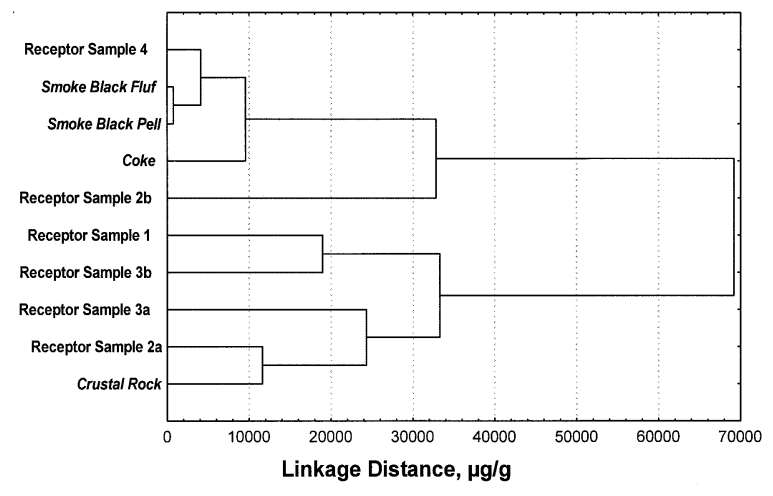

Fig. 3 Dendrogram based on measured concentrations using euclidean distance and complete linkage.

crustal rock, appear. Samples 4 and $2 b$ belong to the cluster of the sources and particularly in the case of sample 4 it is also closer to the smoke black profiles than to the coke profile. Samples $2 \mathrm{a}$ and $3 \mathrm{a}$ lie close to the crustal rock profile. This evaluation clearly indicated that two of the samples were most likely to be far from the crustal rock and close to the potential responsible sources under study. While this part of the analysis did not serve to conclude on the existence of a link between sources and samples, it was useful to assign an order of priority for SEM analysis.

\section{Morphology analysis}

Detailed SEM analysis was performed on all source samples in order to characterize particle morphology. The same study was carried out for the two samples, 4 and $2 b$, which were most likely to be linked to the sources under consideration, and for samples $2 \mathrm{a}$ and $3 \mathrm{a}$, which were located close to the crustal rock according with clustering analysis. The following observations were made through SEM analysis.

Particles that belong to the fluffy smoke sample are porous agglomerates of variable shape and size, between 20 and 200 $\mu \mathrm{m}$ that are formed by submicronic particles of spherical morphology (Fig. 4a). The pelletized smoke black presents a more compacted and greater uniformity in size, large particles are approximately 3 to $5 \mu \mathrm{m}$, and their form is more rounded (Fig. 4b). Although size and form of the particles are different between these two products, there is no distinction in the submicronic particles-smaller than $0.3 \mu \mathrm{m}$ - that conserve rounded and regular characteristics. In summary, both samples present different size but the morphology is equivalent.

Coke presents a great difference with the previous samples with a distribution of particles of varied sizes, some of these particles are formed by agglomerates (Fig. 5). Two range sizes can be distinguished: 1) between 0.5 and $5 \mu \mathrm{m}$ approximately and 2) of approximate size between 50 and $600 \mu \mathrm{m}$. Differences also appear in morphology where coke is formed by agglomerates and particles of irregular crystalline habit with deposits of small particles, 0.1 to $1 \mu \mathrm{m}$, on the surface.

Samples 4 and $2 b$, that appears to be most likely linked to the sources from the screening analysis, exhibit particles of rather uniform size (Fig. 6). Furthermore, morphological characteristics such as homogeneity, round shape and diameters less than $0.3 \mu \mathrm{m}$ observed through SEM in these samples allowed to establish a link with smoke black. On the other hand, the gray color samples (samples $2 \mathrm{a}$ and 3a) exhibit particles of all type and size. Even when SEM analysis was carried out on several of them, looking for similarities with the 
(a)

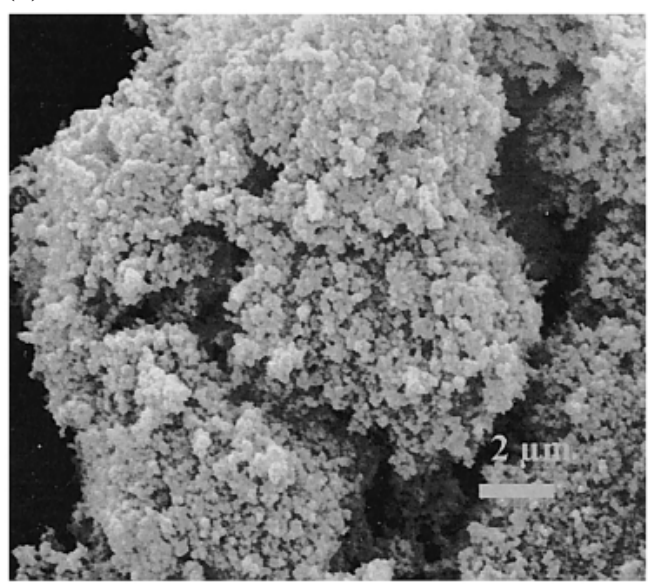

(b)

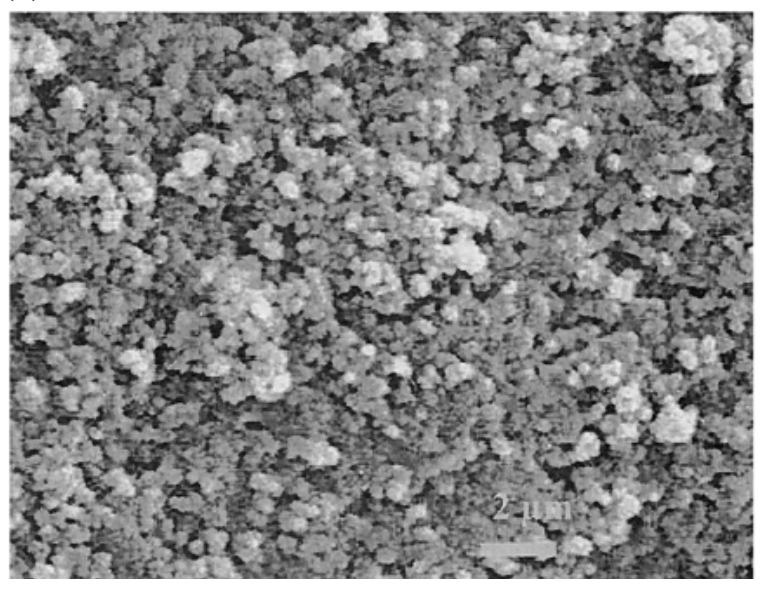

Fig. 4 SEM images of smoke black sample. (a) Fluffy smoke black; (b) pelletized smoke black.

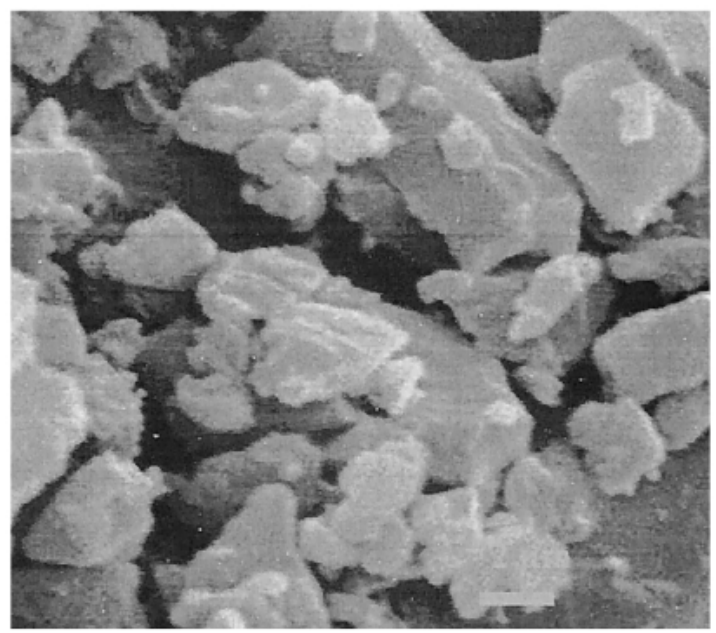

Fig. 5 SEM image of the sample of the coke source.

sources under consideration, this portion of the environmental samples cannot be associated to any particular source.

Observations through SEM indicated that an important fraction of candidate $2 \mathrm{~b}$ and 4 contained particles whose morphology presented great similarity with those from the (a)

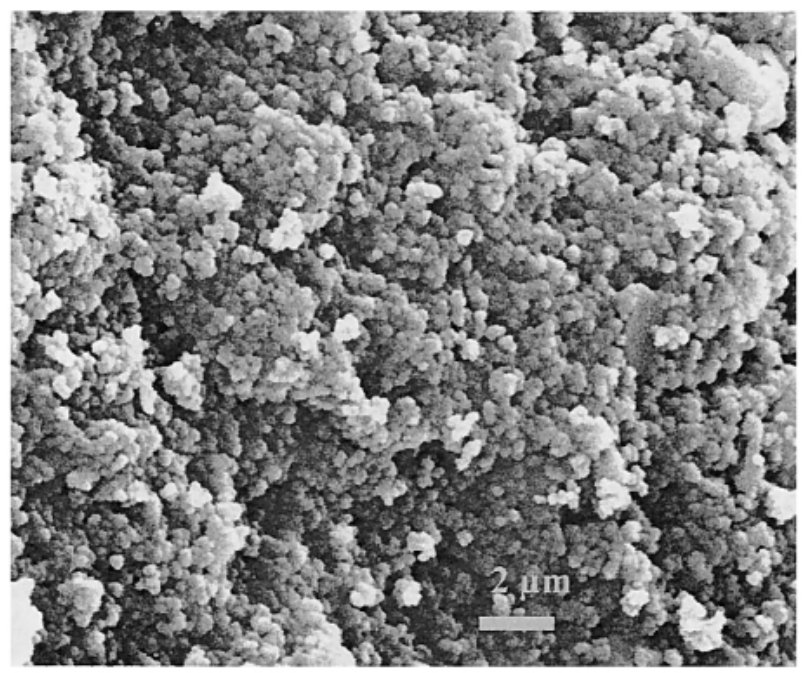

(b)

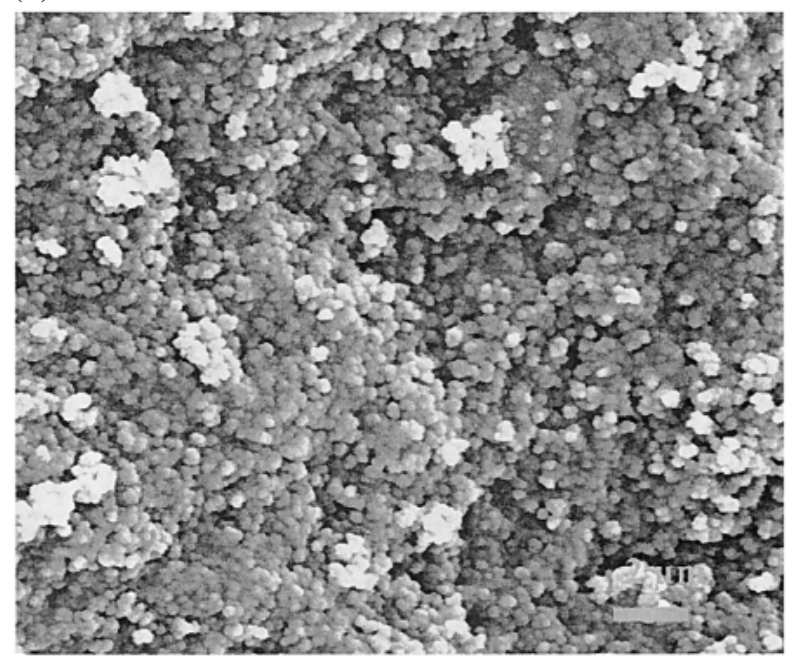

Fig. 6 SEM images of receptor samples. (a) Receptor sample 4; (b) receptor sample $2 \mathrm{~b}$.

smoke black sources. On the other hand, the type of morphology observed for coke is common to different compounds and did not allow a good identification, hindering its use for the identification of the particles collected at the sampling sites by SEM.

Although it is not possible to assure with absolute certainty that the smoke black source has been the solely responsible for the pollution episode, since there may exist other sources that were not detected, the results show the existence of a link between this source and samples $2 \mathrm{~b}$ and 4 .

\section{Conclusions}

The potential of WDXRF to supply multielemental profiles of aerosols has been extensively recognized in air pollution analysis. In this work, WDXRF proved to be an efficient methodology, even in the presence of carbon rich matrices, that allowed a rapid screening through clustering analysis. This permitted to give an order of priority for SEM analysis and a certain guidance to look, within the set of all samples, for those candidates that are most likely to contain particles emitted from 
the sources under consideration.

Lastly, SEM observations allowed establishing a link between this type of samples and one of the suspected sources. Observations through SEM indicated that an important fraction of candidate, samples $2 \mathrm{~b}$ and 4 , contained particles whose morphology presented great similarity with those from the smoke black sources.

This work was not only valuable for the analysis of the pollution episode but also served to point out the need for further characterization of the main sources of airbone particles that may affect the zone. This task constitutes one of the main components for the adequate air pollution control strategy that the City of Campana requires.

\section{Acknowledgements}

The authors are grateful to the Environmental Protection Department of the City of Campana particular to its Head, Laura Meissl, for presenting the problem, supplying all samples and the interest in our work. The National Weather Service provided rainfall statistics for the period under consideration. This work was partially funded under Project PICT 13-0000001833/97 of the Agencia de Promoción Científica y Tecnológica of Argentina.

\section{References}

1. L. Gidhagen, E. Sán Román, D. Gómez, and D. von Bauer, "The Air Quality Situation in Campana and Zárate, Argentina-a Diagnostic Study Including
Recommendations on Future Air Quality Monitoring", World Bank Project ARG96/019/B/01/99, Final Report, Buenos Aires, 1997.

2. A. Viksna, E. Selin Lindaren, P. Standzenieks, and J. Jacobsson, X-Ray Spectrom., 2004, 33(6), 414.

3. C. Bennet, P. Jonsson, and E. Selin Lindgren, X-Ray Spectrom., 2005, 34(1), 1 .

4. W. Vautz, S. Pahl, H. Pilger, M. Schilling, and D Klockow, Atmos. Environ., 2003, 37, 3277.

5. C.-U. Ro, H. Kim, K.-Y. Oh, S. Yea, C. Lee, M. Jang, and R. Van Grieken, Environ. Sci. Technol., 2002, 36, 4770.

6. D. Valiulis, D. Ceburnis, J. Sakalys, and K. Kvietkus, Atmos. Environ., 2002, 36, 6001 .

7. J. I. Godstein, D. Newbury, P. Echlin, D. Joy, C. Fiori, and E. Lifshin, "Scanning Electron Microscopy and X-Ray Micronalysis", 1984, Plenum Press, New York.

8. B. J. Mason, "Introduction to Geochemistry", 3rd ed., 1966, Wiley, New York.

9. U. S. EPA, Volatile organic compound (VOC)/Particulate matter (PM) Speciate data system, Versión 1.5, EPA-450/491-027, U. S. Environmental Protection Agency, Research Triangle Park, 1992.

10. V. Wongphatarakul, S. K. Friedlander, and J. P. Pinto, Environ. Sci. Technol., 1998, 32, 3926.

11. P. Sneath and R. Sokal, "Numerical Taxonomy", The Principles and Practice of Numerical Classification, 1973, Freeman, San Francisco.

12. B. Everitt, "Cluster Analysis", 1981, Heineman, London.

13. L. Kaufman and P. Rousseeuw, "Interpretation of Analytical Data by the Use of Cluster Analysis", 1990, Wiley, New York. 